\title{
EVAPOTRANSPIRAÇÃO E COEFICIENTE DE CULTURA DA ALFACE PARA A REGIÃO SUDOESTE DO PARANÁ
}

\section{EVAPOTRANSPIRATION AND CROP COEFFICIENT OF LETTUCE IN THE SOUTHWEST REGION OF THE STATE OF PARANÁ, BRAZIL}

\author{
Anderson Luis NUNES ${ }^{1}$ \\ Noryam Bervian BISPO ${ }^{2}$ \\ Ricardo Hernandez HERNANDEZ ${ }^{3}$ \\ Lucas NAVARINI ${ }^{4}$
}

\section{RESUMO}

A evapotranspiração da cultura (ETc) e o coeficiente de cultura (Kc) da alface foram determinados em duas épocas do ano (inverno e outono) usando lisímetros de percolação. Durante o inverno e o outono a ETc média observada foi, respectivamente, $162 \mathrm{~mm}$ e $181 \mathrm{~mm}$. O Kc determinado em ambas as épocas do ano atingiu o máximo valor no momento da colheita. No inverno e no outono o valor máximo de Kc foi de aproximadamente 1,40. Este valor é maior do que aqueles recomendados pela FAO $(1,00)$. Pela regressão linear foi verificado que os valores de Kc determinados estão fortemente relacionados com o ciclo de desenvolvimento das plantas.

Palavras-chave: irrigação; lisímetro; consumo de água; Lactuca sativa.

\section{ABSTRACT}

The evapotranspiration (ETc) and crop coefficient $(\mathrm{Kc})$ of lettuce were determined in two growing seasons (winter and autumn) using percolation lysimeters. During the winter and autumn growing seasons, total ETc average observed was, respectively, $162 \mathrm{~mm}$ and $181 \mathrm{~mm}$. The Kc reached in both growing seasons its maximum in the moment of harvest. In winter and autumn the maximum value of $\mathrm{Kc}$ was nearly 1.40. This value is bigger than $\mathrm{Kc}$ suggested by $\mathrm{FAO}(1.00)$. By linear regression was ascertained what Kc values seemed to be strongly related to plant development.

Key-words: irrigation; lysimeter; water consumption; Lactuca sativa.

\footnotetext{
${ }^{1}$ Engenheiro Agrônomo, Doutorando do Programa de Pós-graduação em Fitotecnia da Universidade Federal do Rio Grande do Sul (UFRGS), Professor do Curso de Agronomia da Universidade Tecnológica Federal do Paraná (UTFPR). Porto Alegre-RS, Brasil. E-mail: nunes.ander@gmail.com

${ }^{2}$ Engenheira Agrônoma, Doutoranda do Programa de Pós-graduação em Fitotecnia da Universidade Federal do Rio Grande do Sul (UFRGS), Porto Alegre-RS, Brasil. E-mail: nory.bispo@gmail.com

${ }^{3}$ Engenheiro Agrícola, Doutorando do Programa de Pós-graduação em Engenharia Agrícola da Universidade Estadual do Oeste do Paraná (UNIOESTE). Professor do Curso de Agronomia da Universidade Tecnológica Federal do Paraná (UTFPR). Av. do Conhecimento, km 01 85503-390, Pato Branco-PR. E-mail: rhhe@utfpr.edu.br . Autor para correspondência.

${ }^{4}$ Engenheiro Agrônomo, Doutorando do Programa de Pós-graduação em Agronomia da Universidade Federal de Santa Maria (UFSM), Santa Maria-RS, Brasil. E-mail: lucasnavarini@gmail.com
} 
NUNES, A.L. et al. Evapotranspiração e coeficiente de cultura da alface...

\section{INTRODUÇÃO}

Um dos fatores fundamentais ao bom desenvolvimento de uma cultura é o fornecimento de água de acordo com a sua demanda. Na cultura da alface este fator tem importância, pois disponibilidade hídrica no solo garante folhas (parte comestível) de melhor qualidade. Se esta espécie for cultivada numa situação de deficiência hídrica, ocorrerá uma diminuição significativa na qualidade devido ao acúmulo de látex nas folhas (Andriolo, 2002). Por outro lado, o fornecimento de água em excesso possibilita o surgimento de doenças, principalmente bacterianas. Desta forma, torna-se evidente a importância do fornecimento de água às plantas na dose e no momento adequado, com a finalidade de evitar tanto a falta quanto o excesso.

Para que a água de irrigação seja utilizada de forma racional durante o ciclo, há a necessidade de se determinar a evapotranspiração da cultura (ETc). A razão entre a ETc e a evapotranspiração de referência (ETo) resulta no coeficiente de cultura (Kc). Após a obtenção do Kc é possível estimar a evapotranspiração da cultura utilizando determinações de ETo com base em dados meteorológicos. A ETo é a quantidade de água evapotranspirada na unidade de área e de tempo, por uma cultura de baixo porte, verde, cobrindo totalmente o solo, de altura uniforme e sem deficiência de água, recomendando-se para este caso o uso de grama (Bergamaschi et al., 1999; Farahani et al., 2007). A ETc é função da fase de desenvolvimento da cultura e corresponde à água evapotranspirada por uma cultura qualquer sob condições ótimas de suprimento hídrico (Farahani et al., 2007; Lima \& Silva, 2008).

O Kc é um fator indicativo do consumo de água ideal para a planta. Este índice é comumente adotado como um valor fixo para todo o ciclo de desenvolvimento da planta. Entretanto, o Kc varia mais com o estádio de desenvolvimento do que com a cultura, sendo pequeno no início (pequena fração de solo coberta pela cultura) e atingindo o valor máximo em pleno desenvolvimento da mesma (Bergamaschi et al., 1999; Soares et al., 2001)

$\mathrm{Na}$ agricultura irrigada, o conhecimento da evapotranspiração da cultura nos diferentes estádios de desenvolvimento das plantas cultivadas é fundamental devido a três motivos. O primeiro é em relação à aquisição do direito do uso das águas, tanto de mananciais como de aqüíferos através do instrumento legal da outorga concedida pela Secretaria de Recursos Hídricos, no Estado do Paraná, em que somente é obtida pelo irrigante mediante o consumo de água da cultura a ser irrigada. Diante disso, a informação do consumo real de água pelas plantas ajudará em uma melhor gestão dos recursos. O segundo, é quanto ao dimensionamento dos sistemas de irrigação. Essa informação é fundamental na elaboração de projetos mais precisos e com menor custo de implantação e de manejo. E por fim, é possível fazer o manejo correto da irrigação, diminuindo o consumo de água, energia, insumos e menor incidência de doenças (Alves Júnior et al., 2007). $\mathrm{Na}$ agricultura não irrigada, essa informação também é útil na adoção de práticas culturais que permitam o melhor aproveitamento da água naturalmente disponível em cada região, de modo que os períodos críticos de deficiência hídrica não coincidam com épocas de menor disponibilidade de água no solo (Hunsaker et al., 2007).

A FAO (Allen et al., 1998) apresenta valores de $\mathrm{Kc}$ para quatro estádios de desenvolvimento da alface. Evidentemente, tais valores são aproximados, sendo uma recomendação da FAO que as pesquisas se preocupem em ajustá-los às condições locais de clima, manejo e variedades cultivadas. Assim, o objetivo do presente estudo foi determinar a demanda hídrica para a cultura da alface e derivar coeficientes de cultivo, por meio de lisímetros de percolação na região sudoeste do Paraná.

\section{MATERIAL E MÉTODOS}

Quatro ensaios foram conduzidos em duas épocas (inverno e outono) entre 2001 e 2004, para se obter o Kc para a cultura da alface (Lactuca sativa cv. Verônica) na região sudoeste do Paraná. $\mathrm{Na}$ época do inverno os ensaios I e II foram realizados, respectivamente, entre 30/05 a 11/07/2001 (43 dias) e 30/06 a 10/08/2001 (42 dias). No outono, os ensaios III e IV foram realizados, respectivamente, entre 21/02 a 27/03/2003 (35 dias) e 20/03 a 23/04/2004 (35 dias).

Os ensaios foram realizados em uma área localizada na Universidade Tecnológica Federal do Paraná - Campus Pato Branco $\left(26^{\circ} \mathrm{S}, 52^{\circ} 40^{\prime} \mathrm{W} \mathrm{Gr}\right.$ e altitude de $780 \mathrm{~m}$ anm). O solo é do tipo Latossolo Vermelho-Escuro Distrófico típico, e o clima da região, de acordo com a classificação de Köppen, classifica-se como $\mathrm{Cfa}$ (subtropical úmido com verões quentes). Os dados meteorológicos localizados a $9,6 \mathrm{~km}$ do local dos experimentos, obtidos durante a condução dos ensaios, são apresentados na Tabela 1.

A semeadura dos ensaios foi realizada em bandejas de poliestireno expandido preenchidas com substrato comercial. As bandejas foram submetidas ao sistema floating em ambiente protegido. $\mathrm{O}$ transplante das mudas foi realizado em canteiros com espaçamento entre linhas e entre plantas de 0,25 m. A adubação pré-plantio, baseada em análise do solo, foi feita conforme as recomendações técnicas da cultura. A adubação de cobertura com nitrogênio $\left(60 \mathrm{~kg} \mathrm{ha}^{-1}\right)$ foi realizada em duas épocas: aos 10 e 20 dias após o transplante das mudas em todos os ensaios. 
NUNES, A.L. et al. Evapotranspiração e coeficiente de cultura da alface...

TABELA 1 - Médias por ensaio da temperatura do ar, da umidade relativa do ar, da precipitação e da insolação.

\begin{tabular}{|c|c|c|c|c|c|c|c|c|}
\hline \multirow[b]{2}{*}{ Ensaios } & \multicolumn{5}{|c|}{ Temperatura do $\operatorname{ar}\left({ }^{\circ} \mathrm{C}\right)$} & \multirow[b]{2}{*}{$\begin{array}{c}\text { Umidade } \\
\text { Relativa } \\
\quad(\%)\end{array}$} & \multirow[b]{2}{*}{$\begin{array}{l}\text { Precipita- } \\
\text { ção (mm) }\end{array}$} & \multirow[b]{2}{*}{$\begin{array}{c}\text { Insolação } \\
\text { (h) }\end{array}$} \\
\hline & $\begin{array}{c}\text { Média } \\
\text { Máxi- } \\
\text { ma }\end{array}$ & $\begin{array}{l}\text { Média } \\
\text { Mínima }\end{array}$ & $\begin{array}{c}\text { Máxima } \\
\text { Absolu- } \\
\text { ta }\end{array}$ & $\begin{array}{c}\text { Mínima } \\
\text { Absolu- } \\
\text { ta }\end{array}$ & Média & & & \\
\hline Ensaio I & 20,6 & 10,1 & 26,0 & 0,9 & 14,1 & 75 & 133,5 & 182,4 \\
\hline Ensaio II & 21,2 & 10,6 & 27,6 & 1,1 & 15,0 & 70 & 120,1 & 205,0 \\
\hline Ensaio III & 27,6 & 18,5 & 32,5 & 9,2 & 21,2 & 75 & 118,1 & 235,2 \\
\hline Ensaio IV & 25,3 & 15,3 & 32,1 & 7,7 & 19,1 & 78 & 155,0 & 210,9 \\
\hline
\end{tabular}

Fonte: IAPAR - Pato Branco - PR

Para o controle da umidade do solo foram instalados três tensiômetros de coluna de mercúrio a 10,15 e $30 \mathrm{~cm}$ de profundidade. O potencial matricial de água no solo foi mantido entre $6,08 \mathrm{e}$ $7,9 \mathrm{kPa}$, e era indicado pelo tensiômetro instalado na profundidade em que as raízes das plantas se encontravam. As aspersões em ambas as culturas foram efetuadas regularmente, através de irrigação pressurizada com aspersores fixos com ângulo de ação circular completo, para elevar a umidade do solo à capacidade de campo $(35 \%)$. O momento da colheita da alface foi baseado no desenvolvimento vegetativo, enquanto ainda não se percebia o sabor amargo das folhas.

A ETc e a ETo foram determinadas pela equação (1) através de lisímetros cultivados com a alface e com a grama São Carlos (Anoxonopus affinis), respectivamente. A altura da grama era sempre mantida entre 0,10 e $0,12 \mathrm{~m}$. Valores diários de ETc e ETo foram agrupados em períodos de 7 dias. Os lisímetros de percolação por gravidade possuem área útil de $1,39 \mathrm{~m}^{2}$ e estão localizados no centro de uma área de bordadura $\left(1050 \mathrm{~m}^{2}\right)$ cultivada com alface e com grama (cultura de referência). A drenagem dos lisímetros era realizada por gravidade, e a água era coletada em recipientes com volume de $20 \mathrm{dm}^{3}$ que diariamente eram medidos através de provetas.

$E T=(P+I-D) \times(A \times d)^{-1}$

Sendo: $E T$ - Evapotranspiração (mm/dia); $P$ Precipitação (mm); I - Irrigação $(\mathrm{mm}) ; \quad D$ drenagem (mm); $d$-Período (dias).

Os dados do coeficiente de cultura foram determinados através da equação (2).

$$
\mathrm{Kc}=\mathrm{ETm} \times \mathrm{ETo}^{-1}
$$

Sendo: $K c$ - Coeficiente de cultura (adimensional); ETc - Evapotranspiração da alface $(\mathrm{mm})$; ETo Evapotranspiração de referência $(\mathrm{mm})$.

\section{RESULTADOS E DISCUSSÃO}

A evapotranspiração da cultura (ETc) acumulada durante o ciclo de desenvolvimento da alface mostrou que o consumo de água por ciclo foi menor nos ensaios de inverno (l e II) em comparação aos ensaios de outono (III e IV). Nos ensaios de inverno o consumo total de água por ciclo foi de 160 e $163 \mathrm{~mm}$ (média de $3,88 \mathrm{~mm} \mathrm{dia}^{-1}$ ). Já durante o outono, apesar de o ciclo ter sido uma semana menor que nos ensaios de inverno, o consumo de água foi aproximadamente $13 \%$ maior $(181 \mathrm{~mm}$ em ambos os ensaios; média de $5,17 \mathrm{~mm}$ $\left.\mathrm{dia}^{-1}\right)$. Como no outono a temperatura média do ar é maior, a ET da cultura tende seguir a curva de aumento da temperatura, em relação ao período de inverno (Montenegro et al., 2008).

Os resultados de evapotranspiração da cultura (ETc) e referência (ETo) são apresentados por ensaio, sendo os mesmos plotados na Figura 1. No ensaio I, verificou-se que a ETc chegou ao máximo em $5 \mathrm{~mm}$ dia $^{-1}$ na terceira semana. Já na quarta semana observou-se que houve um decréscimo acentuado na evapotranspiração devido a ocorrência de frente fria. A queda da temperatura do ar (dados não divulgados) diminuiu a atividade metabólica das plantas e, conseqüentemente, o seu desenvolvimento e consumo de água. Era de se esperar que na quarta semana o ETc fosse maior que na semana anterior em função de que neste período, baseado nos ensaios anteriores, a cultura da alface estaria em seu desenvolvimento máximo, como se observou no ensaio II. A ocorrência de frentes frias também diminuiu os valores de ETc na quinta e sexta semana do ensaio II. Constatou-se neste ensaio que a ETc chegou quase a $6 \mathrm{~mm} \mathrm{dia}^{-1}$ em média.

Nos ensaios de outono, verificaram-se maiores valores de ETc em relação aos ensaios de inverno, uma vez que a temperatura do ar foi maior nesta época do ano (dados não publicados). Nestes ensaios verificou-se que a ETc chegou a valores próximos de $7 \mathrm{~mm} \mathrm{dia}^{-1}$ em média. De uma maneira geral, observou-se nos quatro ensaios a tendência de menores valores de ETc ocorrerem na fase de crescimento inicial das plantas, uma vez que o sistema radicular e a área foliar das plantas são incipientes. Nesta fase, há provavelmente uma maior evaporação da água do solo do que transpiração pelas plantas (Teixeira et al., 2007). 
NUNES, A.L. et al. Evapotranspiração e coeficiente de cultura da alface...
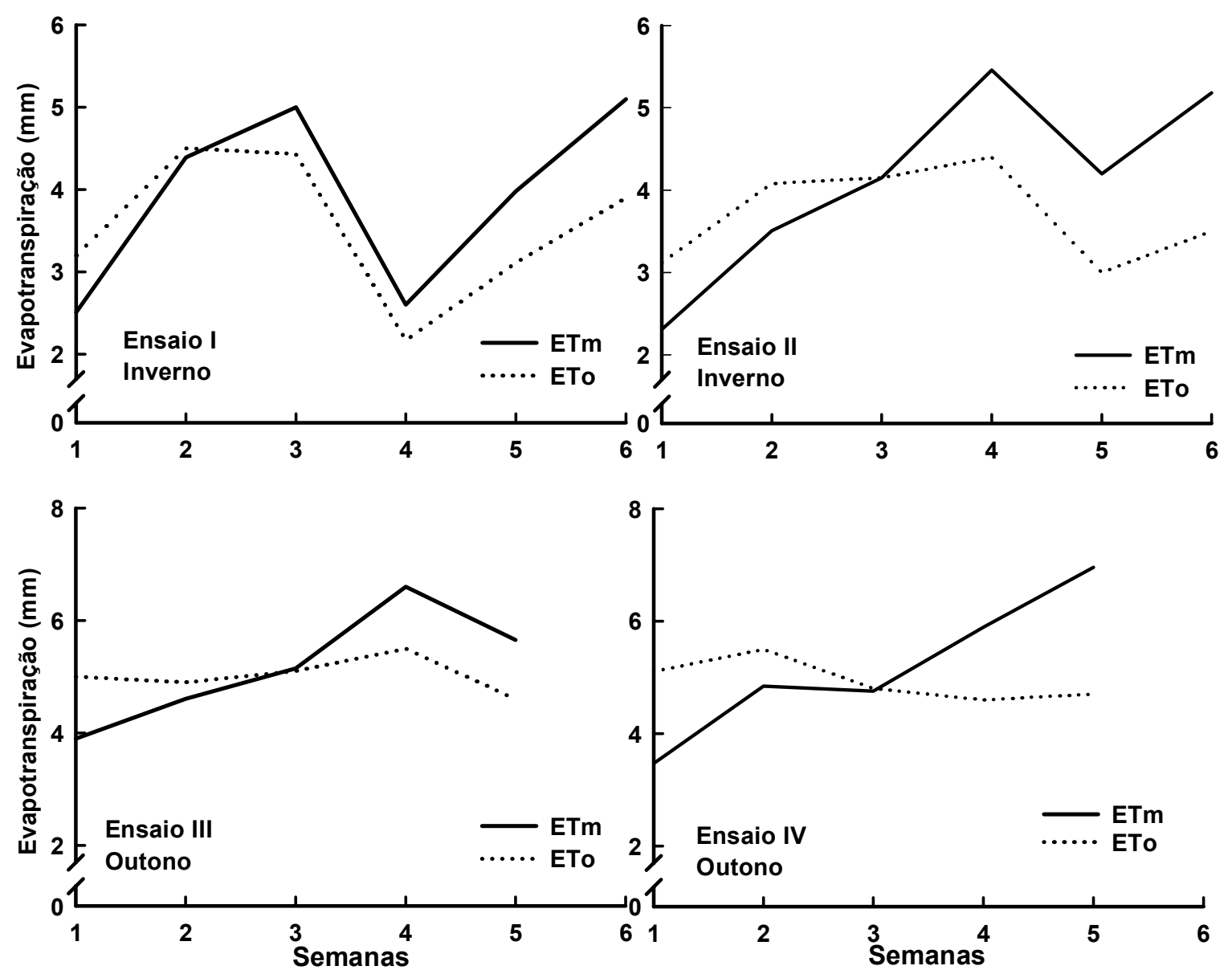

FIGURA 1 - Evapotranspiração da cultura (ETc) e de referência (ETo) da cultura da alface, cultivar Verônica, determinada através de lisímetros de percolação em duas épocas do ano. Pato Branco - PR.

Os valores de Kc foram agrupados por época do ano para facilitar a comparação dos diferentes ensaios em uma mesma época (Figura 2). De uma maneira geral, observou-se a ocorrência dos menores valores de $\mathrm{Kc}$ no início do desenvolvimento da cultura. Com o tempo o Kc assumiu valores maiores que 1,0 quando a ETc é maior que a ETo, devido ao seu crescimento vegetativo. Comparando este estudo com outros, observou-se que os valores de Kc para a cultura da alface na região sudoeste do Paraná são maiores que os reportados na literatura. A FAO recomenda valores entre 0,7 a 1,0 para o cultivo da alface (Allen et al., 1998). Na região de Campinas os valores de Kc para a mesma cultura variam de 0,48 a 0,88 (Bastos et al., 1996). Na Califórnia os valores de Kc para a alface sem deficiência hídrica variaram entre 0,81 e 1,02 (Gallardo et al., 1996). Já para a região central do Arizona foram determinadas curvas de $\mathrm{Kc}$ baseados em diferentes métodos. Os valores máximos de $\mathrm{Kc}$ estimados foram 0,88 (método de Hargreaves), 0,80 (FAO Penman) e
0,81 (FAO Penman-Monteith) (Oliveira et al., 2005). Foi verificado em outras culturas, assim como o verificado neste trabalho com a alface, que o Kc determinado por lisímetros tende a ser maior em relação a aqueles determinados por equações matemáticas (Mendonça et al., 2007).

O comportamento do Kc da alface ao longo do seu desenvolvimento mostra-se diferente em relação a outras culturas. Normalmente, há uma diminuição nos valores do $\mathrm{Kc}$ nas fases finais do desenvolvimento. Este comportamento ocorre em função da maturação fisiológica, época onde as plantas reduzem o consumo de água (Farahani et al., 2008). Na cultura da alface não há a diminuição nos valores finais do Kc, uma vez que a mesma é colhida antes da ocorrência da maturação fisiológica. Isto faz com que o Kc tenha um aumento linear em seus valores. Dessa forma foi possível realizar regressões lineares nos valores médios de Kc de cada época do ano, como pode se observar na Figura 2. 
NUNES, A.L. et al. Evapotranspiração e coeficiente de cultura da alface...
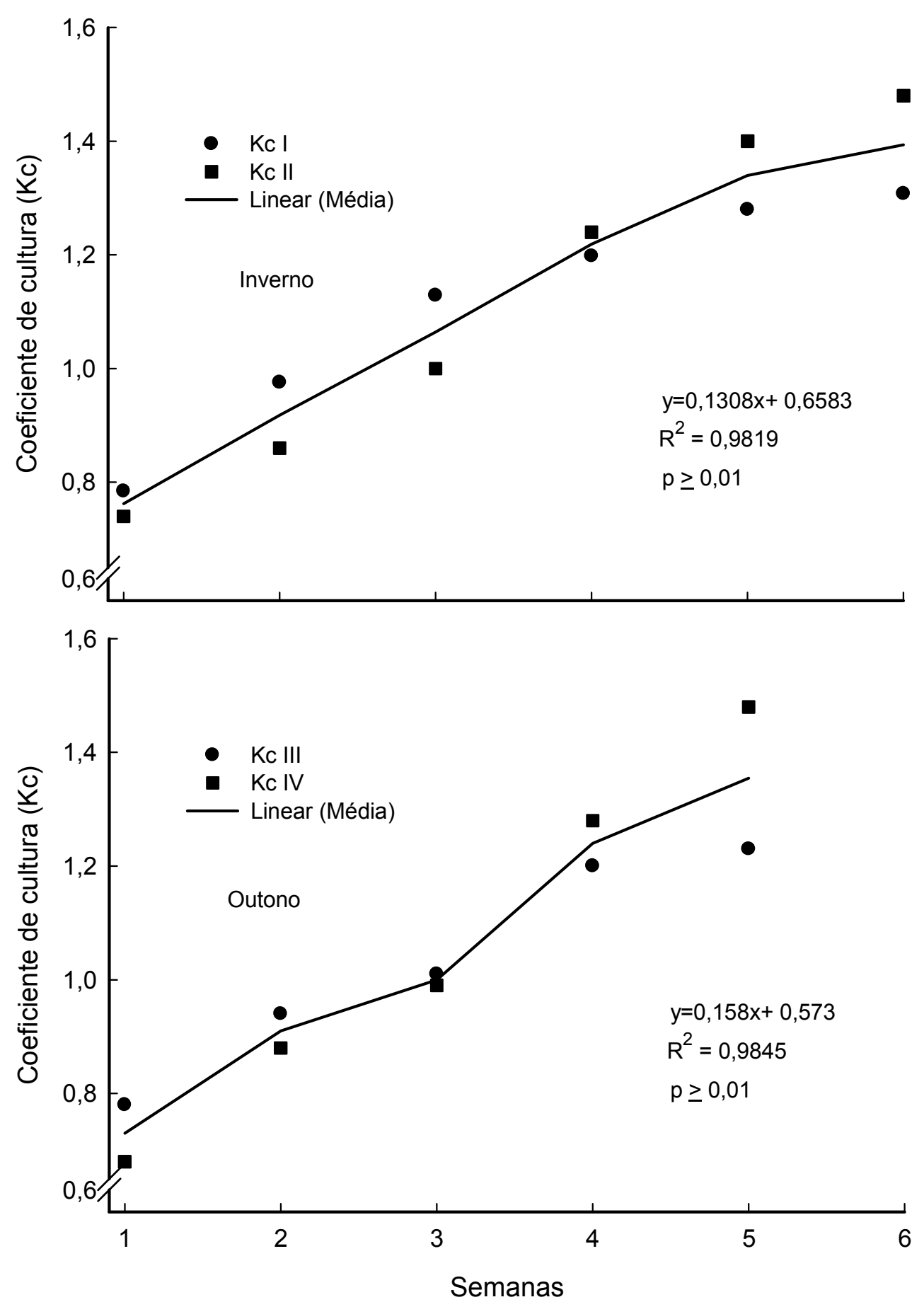

FIGURA 2 - Coeficiente de cultura (Kc) para a cultura da alface, cultivar Verônica, em duas épocas do ano. Pato Branco - PR. 
NUNES, A.L. et al. Evapotranspiração e coeficiente de cultura da alface...

As equações de ajuste mostraram para ambas as épocas do ano que acima de $98 \%$ da variação total dos Kcs pode ser explicada pela variação no seu ciclo de desenvolvimento (semanas). Através do coeficiente angular das equações é possível verificar, durante o inverno, que a cada semana de desenvolvimento na cultura da alface há um aumento de 0,13 nos valores de Kc. Já para o outono este aumento é de 0,16 nos valores de Kc. Isso evidencia um maior consumo de água pelas plantas no período do outono em relação ao inverno.

\section{CONCLUSÕES}

1) A evapotranspiração da cultura da alface foi maior no período de outono (181 mm média de 5,17 $\mathrm{mm} \mathrm{dia}^{-1}$ ) em relação ao inverno (162 $\mathrm{mm}$ - média de $3,88 \mathrm{~mm} \mathrm{dia}^{-1}$ ).

2) Os valores de Kc determinados neste trabalho para a cultura da alface foram maiores do que aqueles recomendados pela FAO.

\section{REFERÊNCIAS}

1. ALLEN, R. G. et al. Crop evapotranspiration: guidelines for computing crop water requirements. Roma: FAO, 1998. (FAO Irrigation and Drainage, 56)

2. ALVES JÚNIOR, J. et al. Determination of the crop coefficient for grafted Tahiti lime trees and soil evaporation coefficient of Rhodic Kandiudalf clay soil in Sao Paulo, Brazil. Irrigation Science, v. 25, n. 4, p. 419-428, 2007.

3. ANDRIOLO, J. L. Olericultura geral: princípios e técnicas. Santa Maria: UFSM, 2002. 140 p.

4. BASTOS, E. A. et al. Determinação dos coeficientes de cultura da alface (Lactuca sativa L.). Irriga, v. 1, n. 3, p. 2-5, 1996.

5. BERGAMASCHI, H. et al. Agrometeorologia aplicada à irrigação. 2. ed. Porto Alegre: Universidade Federal do Rio Grande do Sul, 1999. $125 \mathrm{p}$

6. FARAHANI, $\mathrm{H}$. J. et al. Evapotranspiration: progress in measurement and modeling in agriculture. Transactions of the Asabe, v. 50, n. 5, p. 1627-1638. 2007

7. FARAHANI, H. J.; OWEIS, T. Y.; IZZI, G. Crop coefficient for drip-irrigated cotton in a Mediterranean environment. Irrigation Science, v. 26, n. 5, p. 375-383, 2008.

8. GALLARDO, M. et al. Production and water use in lettuces under variable water supply. Irrigation Science, v. 16, n. 3, p. 125-137, 1996.

9. HUNSAKER, D. J. et al. Wheat irrigation management using multispectral crop coefficients: I. Crop evapotranspiration prediction. Transactions of the Asabe, v. 50, n. 6, p. 2017-2033, 2007

10. LIMA, E. P.; SILVA, E. L. Temperatura base, coeficientes de cultura e graus-dia para cafeeiro arábica em fase de implantação. Revista Brasileira de Engenharia Agrícola e Ambiental, v. 12, n. 3, p. 266-273, 2008.

11. MENDONÇA, J. C. et al. Determinação do coeficiente cultural (Kc) do feijoeiro (Phaseolus vulgaris L.), em Campos dos Goytacazes, RJ. Revista Brasileira de Engenharia Agrícola e Ambiental, v. 11, n. 5, p. 471-475, 2007.

12. MONTENEGRO, A. A. T. et al. Evapotranspiração e coeficiente de cultivo da bananeira para a região litorânea do Ceará Revista Ciência Agronômica, v. 39, n. 2, p. 203-208, 2008.

13. OLIVEIRA, A. S. et al. Water use and crop coefficient of subsurface drip-irrigated lettuce in Central Arizona. Revista Brasileira de Engenharia Agrícola e Ambiental, v. 9, n. 1, p. 37-44, 2005.

14. SOARES, W. R. et al. Dependência do coeficiente de cultura no estádio inicial de desenvolvimento (Kc ini) à lâmina de irrigação e textura do solo. Revista Brasileira de Engenharia Agrícola e Ambiental, v. 5, n. 1, p. 23-27, 2001.

15. TEIXEIRA, A. H. C., BASTIAANSSEN, W. G. M.; BASSOI, L. H. Crop water parameters of irrigated wine and table grapes to support water productivity analysis in the Sao Francisco river basin, Brazil. Agricultural Water Management, v. 94, $n$. $1-3$, p. 31-42, 2007

Recebido em 25/08/2008 Aceito em 12/06/2009 